\title{
Mandated community treatment: a promising concept for world psychiatry? John Monahan
}

\author{
Address: University of Virginia School of Law, 580 Massie Road, Charlottesville, Virginia 22903, USA \\ from WPA Thematic Conference. Coercive Treatment in Psychiatry: A Comprehensive Review \\ Dresden, Germany. 6-8 June 2007 \\ Published: 19 December 2007 \\ BMC Psychiatry 2007, 7(Suppl I):S7 doi:I0.1 I86/I47|-244X-7-SI-S7
}

This abstract is available from: http://www.biomedcentral.com//47I-244X/7/SI/S7

C 2007 Monahan; licensee BioMed Central Ltd.

Much of the international debate on "outpatient commitment" or "community treatment orders" assumes that court-ordered treatment in the community is simply an extension of long-existing policies authorizing involuntary commitment as a hospital inpatient. In fact, however, outpatient commitment is only one of many forms of "leverage" being used to mandate adherence to psychiatric treatment in community settings. In the social welfare system, benefits disbursed by money managers and the provision of subsidized housing are both used to assure treatment adherence. Similarly, for people who commit a criminal offense, adherence to psychiatric treatment may be made a condition of probation. Favorable disposition of a case by a mental health court may also be tied to treatment participation. Psychiatric advance directives can be thought of as a form of "selfmandated" treatment. The MacArthur Foundation's Research Network on Mandated Community Treatment is engaged in a broad program of research on the uses of leverage to promote adherence to psychiatric services in the United States. 